\title{
Pyruvate Dehydrogenase Deficiency Presenting as Intermittent Isolated Acute Ataxia
}

Authors

Affiliations
F.-G. Debray ${ }^{1}$, M. Lambert ${ }^{1}$, R. Gagne², B. Maranda², R. Laframboise² ${ }^{2}$ N. MacKay ${ }^{3}$, B. H. Robinson ${ }^{3}$, G. A. Mitchell ${ }^{1}$

Division of Medical Genetics, Department of Pediatrics, CHU Sainte-Justine, Université de Montreal, Montreal, Québec, Canada 2Department of Medical Genetics, CHU of Quebec and Laval University, Quebec, Canada

Metabolism Research Program, Research Institute, Departments of Pediatrics and Biochemistry, The Hospital for Sick Children, University of Toronto, Toronto, Ontario, Canada
Key words

- episodic ataxia

- intermittent symptoms

- pyruvate dehydrogenase deficiency received 05.07.2007

accepted

after revision 19.04.2008

Bibliography

DOI $10.1055 / \mathrm{s}-2008-1077084$

Neuropediatrics 2008;

39: $1-4$

c) Georg Thieme Verlag KG

Stuttgart · New York

ISSN 0174-304X

\section{Correspondence}

\section{G. A. Mitchell, MD}

Medical Genetics Division

CHU Sainte-Justine

3175 Côte Sainte-Catherine

Montréal

Québec H3T 1C5

Canada

Tel.: + 1/514/345 4727

Fax: + 1/514/345 4766

grant.mitchell@recherche-ste-

justine.qc.ca

\section{Abstract}

$\nabla$

Objective: The aim of this study is to report and emphasize unusual presentations of pyruvate dehydrogenase (PDH) deficiency (OMIM 312170).

Methods: PDH activity and PDHA1 gene were studied in two siblings presenting with intermittent ataxia in childhood. Similar presentations in reported $\mathrm{PDH}$-deficient patients were searched for using the Medline database.

Results: Both patients had PDH deficiency caused by a new mutation (G585C) in the PDHA1 gene, which is predicted to replace a highly conserved glycine at codon 195 by alanine. Although this mutation lies within the thiamine pyrophosphate binding domain, there was no thiamine responsiveness in vivo. The patients presented recurrent episodes of acute isolated ataxia in infancy. Both had normal blood and CSF lactate levels. Although symptoms initially resolved between episodes during the first decade, both patients subsequently worsened and developed progressive and severe encephalopathy, leading to death in their twenties. The spectrum of intermittent presentations in PDH deficiency includes episodic ataxia, intermittent peripheral weakness, recurrent dystonia and extrapyramidal movement disorders.

Conclusions: PDH deficiency should be considered in patients with unexplained intermittent and recurrent acute neurological symptoms. Long-term prognosis and outcome remain uncertain. PDH deficiency can occur even with normal CSF lactate concentration.

$\begin{array}{ll}\text { Abbreviations } \\ \nabla \\ \text { CSF } & \text { cerebrospinal fluid } \\ \text { DCA } & \text { dichloroacetate } \\ \text { L/P } & \text { lactate to pyruvate } \\ \text { MRI } & \text { magnetic resonance imaging } \\ \text { PDH } & \text { pyruvate dehydrogenase }\end{array}$

\section{Introduction} $\nabla$

Pyruvate dehydrogenase (PDH) is an essential rate-limiting enzyme connecting glycolysis with the tricarboxylic acid cycle and oxidative phosphorylation [16]. PDH deficiency is heterogeneous both clinically and at the biochemical and molecular levels. Most PDH complex deficiencies result from mutations in the $\mathrm{X}$-linked $\mathrm{E} 1 \alpha$ subunit gene (PDHA1). Clinical presentations range from fatal neonatal lactic acidosis to chronic nonprogressive encephalopathy $[15,16]$.

\section{Patients and Methods \\ V \\ Case reports}

Patient 1, born at term to unrelated parents, had a normal neonatal period and early development. He walked without support at 12 months. At 18 months, he was admitted for acute ataxia during an upper respiratory tract infection. Over two weeks, he spontaneously improved and became asymptomatic. At 30 months, acute ataxia recurred during a febrile illness, lasting several days. In the following years, he had recurrent episodes of isolated ataxia, approximately twice a year, often triggered by viral infections. In blood and CSF, lactate was 1.83 and $1.87 \mathrm{mmol} / \mathrm{L}$ (normal: <2.2), with lactate-to-pyruvate $(\mathrm{L} / \mathrm{P})$ ratios of 30.2 and 34.6 (normal: <20), respectively. At this time, complete recovery was noted between episodes and he continued in regular school. At age 8 years, he became suddenly ill, complained of headache and was admitted for respiratory distress requiring mechanical ventilation. Cerebral 
MRI revealed focal hyperintensities in the perisylvian cortex and the brain stem. Respiratory chain and PDH activities measured in fibroblasts revealed PDH deficiency. Thereafter, he had persistent truncal ataxia, unsteadiness of gait and his neurological status progressively worsened. Thiamine was administered at age 10 years ( $150 \mathrm{mg}$ daily) without clinical effect. At age 11 years, he had lost the ability to walk. His speech was dysarthric and he developed swallowing disturbances. In the following years, he continued to deteriorate, presenting seizure, tremor, left hemiparesis followed by progressive spastic tetraparesis. Ketogenic diet was tried for several months without improvement. Evolution was marked by severe central hypoventilation requiring tracheostomy and chronic ventilation until death at age 20 years.

Patient 2 was the younger brother of patient 1 . Perinatal period and early development were normal. He walked unaided at 12 months. A few weeks later, parents noticed unsteady gait and he stopped walking until 18 months. At 3 years, he presented acute ataxia after a viral infection. Over two weeks, he completely recovered. Another ataxic episode recurred six months later. PDH deficiency was diagnosed. He continued to present recurrent ataxic episodes (twice a year) separated by symptom-free periods. Lactate in blood and CSF was $1.18 \mathrm{mmol} / \mathrm{L}$ and $1.41 \mathrm{mmol} / \mathrm{L}$, and $\mathrm{L} / \mathrm{P}$ ratio, 22.1 and 18.5 , respectively. He received thiamine $(250 \mathrm{mg} /$ day $)$ but progressively deteriorated after age of 10 years, developing seizure, dysarthria, tremor, spastic tetraparesis and severe encephalopathy, leading to death at age 21 years.

\section{Methods}

$\nabla$

PDH activities in the native and dichloroacetate-activated states and PDH subunit activities were measured in cultured fibroblasts as described [18]. An E1 $\alpha$ mutation was detected by cDNA amplification and sequencing as described [4]. The PCR primers were PDHE $1 \alpha$-F, 5'-CTCCTGGGTTGTGAGGAGTC-3' and PDHE $1 \alpha-$ R, 5'-TGGTAGCCCCCTGAAGCTAT-3' ( $\mathrm{T}_{\mathrm{a}}$ 55 ${ }^{\circ}$, 1248-bp amplicon); PDH2/3-F, 5'-CAGGGTGGAAGAGAAGCCTA-3' and PDH2/3-R, 5' CCACCACAAACCTACCACTC-3' (Ta $54^{\circ}, 965-b p$ amplicon); PDH7F, 5'-AGCCAAATGAAACCCCTTTT-3' and PDH7-R, 5'-AATGTCACTACGGGAGACGTG-3' ( $\mathrm{T}_{\mathrm{a}} 54^{\circ}$, 210-bp amplicon). Biochemical and molecular studies were performed with informed consent of patients or their legal guardians. We examined available clinical data in reported PDH deficient patients presenting with intermittent ataxia, using Medline database searches.

\section{Results}

$\nabla$

Results of enzyme studies performed in fibroblasts are shown in - Table 1. Molecular studies revealed a single base pair substitution $585 \mathrm{G}>\mathrm{C}$ in the PDHA1 gene in both patients. Clinical features of reported PDH-deficient patients initially presenting with intermittent ataxia are summarized in Table 2 $[1,2,9,10,12-15]$.

\section{Table 1 Enzyme studies}

\begin{tabular}{|c|c|c|}
\hline & Patient 1 & Patient 2 \\
\hline $\mathrm{PDH}_{\text {native }}^{\mathrm{a}}$ & $0.350 \pm 0.047[35]$ & $0.175 \pm 0.028[18]$ \\
\hline PDH DCA-activated ${ }^{\mathrm{a}}$ & $0.408 \pm 0.056[31]$ & $0.235 \pm 0.057[14]$ \\
\hline \multicolumn{3}{|l|}{ PDH subunits } \\
\hline - pyruvate decarboxylase ${ }^{\mathrm{b}}(\mathrm{E} 1)$ & $0.55 \pm 0.25[27]$ & not done \\
\hline $\begin{array}{l}\text { - dihydrolipoyl transacetylase }{ }^{a} \\
\text { (E2) }\end{array}$ & $15.1[116]$ & not done \\
\hline $\begin{array}{l}\text { - lipoamide dehydrogenase }{ }^{\mathrm{a}} \\
\text { (E3) }\end{array}$ & $4.4[85]$ & not done \\
\hline \multicolumn{3}{|l|}{ anmoles/min/mg protein } \\
\hline \multicolumn{3}{|l|}{ bnmoles/h/mg protein } \\
\hline $\begin{array}{l}\text { DCA, dichloroacetate. Values are } \mathrm{m} \\
\text { shown in brackets }\end{array}$ & \pm SD, Percentage & control mean is \\
\hline
\end{tabular}

Table 2 PDH-deficient patients initially presenting with intermittent ataxia

\begin{tabular}{|c|c|c|c|c|c|c|c|c|c|c|c|c|c|}
\hline \multirow[t]{2}{*}{ Pt } & \multirow[t]{2}{*}{ Sex } & \multirow{2}{*}{$\begin{array}{l}\text { Age at } \\
\text { onset }\end{array}$} & \multirow[b]{2}{*}{ frequency } & \multicolumn{2}{|c|}{ Episodes of ataxia } & \multirow{2}{*}{$\begin{array}{l}\text { Thia- } \\
\text { mine re- } \\
\text { sponse }\end{array}$} & \multicolumn{4}{|c|}{ Follow-up - last reported status } & \multirow{2}{*}{$\begin{array}{l}\text { PDH } \\
\text { act }^{\mathrm{a}}\end{array}$} & \multirow{2}{*}{$\begin{array}{l}\text { E1 } \alpha \text { mu- } \\
\text { tation }\end{array}$} & \multirow[t]{2}{*}{ Ref } \\
\hline & & & & duration & other symptoms & & evolution & age & living & cognitive & & & \\
\hline 1 & M & $16 \mathrm{~m}$ & $2-6 / y$ & $<1 w$ & $\begin{array}{l}\text { dystonia, } \\
\text { choreaoathetosis }\end{array}$ & na & steady & $8 y$ & + & $\mathrm{n}$ & 18 & na & {$[2]$} \\
\hline 2 & M & $4 y$ & $3-4 / y$ & $\sim 3 w$ & $\begin{array}{l}\text { dysarthria, } \\
\text { hyperventilation }\end{array}$ & na & progressive & $45 y$ & - & impaired & na & na & [9] \\
\hline 3 & M & $18 \mathrm{~m}$ & $1 / \mathrm{m}$ & $2-3 d$ & $\begin{array}{l}\text { dysarthria, } \\
\text { hyperventilation }\end{array}$ & - & $\begin{array}{l}\text { progres- } \\
\text { sive }>15 y\end{array}$ & $24 y$ & - & impaired & na & na & [9] \\
\hline 4 & M & $7 y$ & $6-8 / y$ & $<1 w$ & $\begin{array}{l}\text { dysarthria, } \\
\text { hyperventilation }\end{array}$ & - & $\begin{array}{l}\text { progres- } \\
\text { sive }>13 y\end{array}$ & $22 y$ & + & impaired & 46 & na & {$[1]$} \\
\hline 5 & M & na & na & na & dysarthria & na & steady & $16 y$ & + & $\mathrm{n}$ & 5 & na & [15] \\
\hline 6 & M & na & na & na & - & na & steady & $6 y$ & + & $\mathrm{n}$ & 61 & na & [15] \\
\hline 7 & M & $17 \mathrm{~m}$ & na & na & $\begin{array}{l}\text { hypotonia, } \\
\text { weakness }\end{array}$ & + & steady & $8 y$ & + & $\mathrm{n}$ & 35 & na & [14] \\
\hline 8 & M & $6 \mathrm{~m}$ & $2-4 / y$ & weeks & tremor, areflexia & + & steady & $11 y$ & + & $\mathrm{n}$ & 25 & V71A & [12] \\
\hline 9 & M & $3 y$ & $1 / y$ & days & weakness, areflexia & + & steady & $14 y$ & + & na & 19 & R263G & [10] \\
\hline 10 & M & $24 m$ & na & na & weakness & + & steady & $8 y$ & + & $\mathrm{n}$ & 45 & L216F & [13] \\
\hline 11 & M & $18 \mathrm{~m}$ & $2 / y$ & $1-2 w$ & $\begin{array}{l}\text { dysarthria, } \\
\text { swallowing problems }\end{array}$ & - & $\begin{array}{l}\text { progres- } \\
\text { sive }>8 \text { y }\end{array}$ & $20 y$ & - & impaired & 35 & G195A & pt 1 \\
\hline 12 & $M$ & $12 \mathrm{~m}$ & $2 / y$ & $2 w$ & tremor, dysarthria, & - & $\begin{array}{l}\text { progres- } \\
\text { sive }>10 y\end{array}$ & $21 y$ & - & impaired & 18 & G195A & pt 2 \\
\hline
\end{tabular}




\section{Discussion}

\section{$\nabla$}

We report the long-term follow-up of two brothers with PDH deficiency initially presenting with recurrent episodes of isolated acute ataxia with complete recovery between episodes. An important clue for the suspicion of PDH or respiratory chain deficiencies is a raised lactate concentration in blood. Nevertheless, blood lactate can be normal in some PDH-deficient patients, whereas being typically elevated in CSF [3]. We report to the best of our knowledge, the first cases of biochemically and molecularly proven PDH-deficient patients with normal lactate levels in CSF, underlining that PDH deficiency should be considered even in the absence of increased CSF lactate concentration. In PDH deficiency, the L/P molar ratio is typically low, consistent with an unimpaired cytoplasmic redox state [16]. Paradoxally, our patient 1 had a mildly elevated L/P ratio in blood and CSF. The discriminant power of the L/P ratio was shown to increase at higher lactate concentrations, and this case illustrates the lack of significance of the L/P ratio when lactate is in the normal range [6].

PDH deficiency is clinically heterogeneous. A small subset of patients presents with an atypically mild course, with intermittent neurological symptoms often triggered by infectious illness. This phenotype is incompletely characterized, poorly emphasized in the medical literature, and possibly underdiagnosed. Blass et al. first reported in 1970 an intermittent movement disorder in PDH deficiency [2]. Since this description, only a handful of patients were reported for which intermittent ataxia was the presenting feature ( $\bullet$ Table 2 ). Notably, all were male. Median age at first ataxic event was 18 months. Frequency of episodes ranged from once a month to once a year. Remarkably, 5/12 patients showed a late-onset progressive neurodegenerative course. In contrast, 6/12 were cognitively unimpaired at last follow-up (median age: 8 years). Many patients with intermittent ataxia have presented in their clinical course some signs of basal ganglia or brainstem dysfunction: hyperventilation, dysarthria, dystonia or choreoathetosis ( $\bullet$ Table 2 ). Although these symptoms initially resolved between episodes, it suggests a continuum in the disease severity spectrum, ending with typical Leigh syndrome.

In addition to intermittent ataxia, recurrent acute dystonia [7], episodic peripheral weakness sometimes mimicking GuillainBarre syndrome $[5,19]$, and complex extrapyramidal movement disorders in adults [11] were more recently recognized in PDH deficiency. This stresses the necessity to consider PDH deficiency in any patient with unexplained recurrent acute neurological symptoms, even in the absence of chronic neurological impairment. Importantly, PDH deficiency can be improved by specific treatment: thiamine, ketogenic diet and dichloroacetate [16].

The cG585C mutation in the PDHA1 gene, although briefly mentioned in a summary table [4], has never been observed in any other patient. It predicts the replacement of a highly conserved glycine to alanine (G195A). Although this change affects the thiamine pyrophosphate binding domain (TPP-BD), thiamine failed to improve our patients. Currently, 6 other mutations are known in the E1 $\alpha$-TPP-BD: A199T, M210V, W214R, P217L, F205L, L216F [8,13]. Only the last two were thiamineresponsive in vivo. In contrast, several mutations outside the TPP-BD were thiamine-sensitive $[8,14]$. Because the dimer of $\alpha-\beta$ E1 subunits is held together by TPP, it undoubtedly functions to stabilize the $\alpha_{2} \beta_{2}$ complex, even when mutations are outside the TPP-BD. Indeed, mutations outside this site allow for normal TPP binding, stabilizing the protein. For example, thiamine responsiveness was demonstrated for a patient with the three C-terminal amino acids truncated [17]. Probably G195A in the TPP-BD precludes this stabilization from occurring. In practice, thiamine should be tried in all PDH-deficient patients. Those with milder phenotypes (i.e., intermittent presentations) and higher residual enzyme activity are more susceptible to be thiamine-responsive.

In summary, we report two patients with PDH deficiency presenting with recurrent episodes of isolated acute ataxia. This unusual mode of presentation highlights the phenotypic variability in PDH deficiency. Although only few patients were described in the literature, the occurrence of other types of intermittent neurological symptoms (including episodic weakness, acute dystonia and choreoathetosis) suggests that intermittent presentation could be an underestimated and underdiagnosed phenotype of PDH deficiency. PDH deficiency should be considered in patients with unexplained recurrent acute neurological symptoms.

\section{References}

1 Bindoff LA, Birch-Machin MA, Farnsworth L, Gardner-Medwin D, Lindsay JG, Turnbull DM. Familial intermittent ataxia due to a defect of the E1 component of pyruvate dehydrogenase complex. J Neurol Sc 1989; 93: 311-318

2 Blass JP, Avigan J, Uhlendorf BW. A defect in pyruvate decarboxylase in a child with an intermittent movement disorder. J Clin Invest 1970; 49: 423-432

3 Brown GK, Haan EA, Kirby DM, Scholem RD, Wraith JE, Rogers JG et al. Cerebral lactic acidosis: defects in pyruvate metabolism with profound brain damage and minimal systemic acidosis. Eur J Pediatr 1988; 147: 10-14

4 Cameron JM, Levandovskiy V, Mackay N, Tein I, Robinson BH. Deficiency of pyruvate dehydrogenase caused by novel and known mutations in the E1 alpha gene. Am J Med Genet A 2004; 131: 59-66

5 Debray FG, Lambert M, Vanasse M, Decarie JC, Cameron J, Levandovskiy V et al. Intermittent peripheral weakness as the presenting feature of pyruvate dehydrogenase deficiency. Eur J Pediatr 2006; 165: 462-466

6 Debray FG, Mitchell GA, Allard P, Robinson BH, Hanley JA, Lambert M. Diagnostic accuracy of blood lactate-to-pyruvate molar ration in the differential diagnosis of congenital lactic acidosis. Clin Chem 2007; 53: 916-921

7 Head RA, Goede CG de, Newton RW, Walter JH, MacShane M, Brown RM et al. Pyruvate dehydrogenase deficiency presenting as dystonia in childhood. Dev Med Child Neurol 2004; 46: 710-712

8 Lissens W, DeMeirleir L, Seneca S, Liebars I, Brown GK, Brown RM et al. Mutation in the X-linked pyruvate dehydrogenase (E1) alpha subunit gene (PDHA1) in patients with a pyruvate dehydrogenase complex deficiency. Hum Mutat 2000; 15: 209-219

9 Livingstone IR, Gardner-Medwin D, Pennington RJ. Familial intermittent ataxia with possible X-linked recessive inheritance. Two patient with abnormal abnormal pyruvate metabolism and a response to acetazolamide. J Neurol Sci 1984; 64: 89-97

10 Marsac C, Beneli C, Desguerre I, Diry M, Fouque F, Meirleir L De et al. Biochemical and genetic studies of tour patients with pyruvate dehydrogenase E1 alpha deficiency. Hum Genet 1997; 99: 785-792

11 Mellick G, Price L, Boyle R. Late-onset presentation of pyruvate dehydrogenase deficiency. Mov Disord 2004; 19: 727-729

12 Naito E, Ito M, Yokota I, Saijo T, Ogawa Y, Kuroda Y. Diagnosis and molecular analysis of three male patients with thiamine-responsive pyruvate dehydrogenase complex deficiency. J Neurol Sci 2002; 201: 33-37

13 Naito E, Ito M, Yokota I, Saijo T, Matsuda J, Ogawa Y et al. Thiamineresponsive pyruvate dehydrogenase deficiency in two patients caused by a point mutation (F205L and L216F) within the thiamine pyrophosphate binding region. Biochem Biophys Acta 2002; 1588: 79-84

14 Old SE, DeVivo DC. Pyruvate dehydrogenase complex deficiency: biochemical and immunoblot analysis of cultured skin fibroblasts. Ann Neurol 1989; 26: 746-751 
15 Robinson BH, MacMillan H, Petrova-Benedict R, Sherwood WG. Variable clinical presentation with defective E1 component of the pyruvate dehydrogenase complex. J Pediatr 1987; 111: 525-533

16 Robinson BH. Lactic acidemia. In: Scriver CR, Beaudet AL, Sly WS, Valle D, (eds). The metabolic and molecular bases of inherited disease 8th edn. New York: McGraw-Hill 2001; 2275-2295

17 Seyda A, MacEachern G, Haas R, Robinson BH. Sequential deletion of C-terminal amino acids of the $\mathrm{E}(1)$ alpha component of the PDH complex leads to reduced steady-state levels of functional E(1)alpha(2)beta(2) tetramers:implications for patients with PDH deficiency. Hum Mol Genet 2000; 9: 1041-1048
18 Sheu $K F, H u C W$, Utter MF. Pyruvate dehydrogenase complex activity in normal and deficient fibroblasts. J Clin Invest 1981; 67: 1463-1471 19 Strassburg HM, Koch J, Mayr J, Sperl W, Bolthauser E. Acute flaccid paralysis as initial symptom in 4 patients with novel E1a mutations of the pyruvate dehydrogenase complex. Neuropediatrics 2006; 37 : 137-141 